\title{
Quantification of the whole-body burden of radiographic osteoarthritis using factor analysis
}

\author{
Amanda E Nelson ${ }^{1 *}$, Robert F DeVellis ${ }^{1,2}$, Jordan B Renner ${ }^{1,3}$, Todd A Schwartz ${ }^{1,4}$, Philip G Conaghan ${ }^{5}$, \\ Virginia B Kraus ${ }^{6}$ and Joanne M Jordan ${ }^{1}$
}

\begin{abstract}
Introduction: Although osteoarthritis (OA) commonly involves multiple joints, no widely accepted method for quantifying whole-body OA burden exists. Therefore, our aim was to apply factor analytic methods to radiographic $\mathrm{OA}(\mathrm{rOA})$ grades across multiple joint sites, representing both presence and severity, to quantify the burden of rOA.

Methods: We used cross-sectional data from the Johnston County Osteoarthritis Project. The sample $(n=2092)$ had a mean age of $65 \pm 11$ years, body mass index (BMI) $31 \pm 7 \mathrm{~kg} / \mathrm{m}^{2}$, with $33 \%$ men and 34\% African Americans. A single expert reader (intra-rater $\kappa=0.89$ ) provided radiographic grades based on standard atlases for the hands (30 joints, including bilateral distal and proximal interphalangeal [IP], thumb IP, metacarpophalangeal [MCP] and carpometacarpal [CMC] joints), knees (patellofemoral and tibiofemoral, 4 joints), hips (2 joints), and spine (5 levels [L1/2 to L5/S1]). All grades were entered into an exploratory common factor analysis as continuous variables. Stratified factor analyses were used to look for differences by gender, race, age, and cohort subgroups.

Results: Four factors were identified as follows: IP/CMC factor (20 joints), MCP factor (8 joints), Knee factor (4 joints), Spine factor ( 5 levels). These factors had high internal consistency reliability (Cronbach's $\alpha$ range 0.80 to 0.95), were not collapsible into a single factor, and had moderate between-factor correlations (Pearson correlation coefficient $r=0.24$ to 0.44). There were no major differences in factor structure when stratified by subgroup.

Conclusions: The 4 factors obtained in this analysis indicate that the variables contained within each factor share an underlying cause, but the 4 factors are distinct, suggesting that combining these joint sites into one overall measure is not appropriate. Using such factors to reflect multi-joint rOA in statistical models can reduce the number of variables needed and increase precision.
\end{abstract}

Keywords: Radiography, osteoarthritis, factor analysis

\section{Introduction}

Generalized osteoarthritis (OA) as a disease entity has been described for well over 100 years [1]. In 1952, Kellgren described multiple joint OA involvement (feet, facet joints, knees, hips, and other limb joints) among individuals with Heberden's nodes and/or carpometacarpal (CMC) OA [2]. He states in this paper that although many individuals had "polyarticular OA" without nodes or CMC OA, "we are not yet prepared to make this diagnosis [primary generalized OA] in the absence of Heberden's nodes or arthritis of the first CMC joints

\footnotetext{
* Correspondence: aenelson@med.unc.edu

'Thurston Arthritis Research Center, University of North Carolina, 3300

Thurston Building CB 7280, Chapel Hill, NC, 27599, USA Full list of author information is available at the end of the article
}

[2]." Since that time, published reports have defined generalized $\mathrm{OA}$ in a variety of ways, including nodal with large joint $\mathrm{OA}$, more than three or five joints or joint sites involved [3], summed numbers or grades of affected joints [4-7], multiple hand joints [8], or nodal hand OA with other joints involved [9]. However, there remains no widely accepted and universally used definition of generalized OA in the literature despite widespread use of the term itself.

This lack of an accepted definition makes it difficult to quantify the effect of multiple joint involvement on OA outcomes, leading to the common practice of focusing on a single joint site without considering the contribution of other involved sites. This is particularly problematic in the setting of systemic factors, such as
Ciomed Central 
functional disability, performance-based outcomes requiring the use of multiple joint sites, serum/urine biomarkers, and genetics, which are necessarily a reflection of the whole-body burden of OA and the impact of that burden on the individual. In this setting, it would be advantageous to have a parsimonious composite measure(s) that could be included in a statistical model to account for the whole-body burden of OA.

Factor analysis, a method used for 80 years in the social sciences [10-12], provides a way to determine whether a set of variables has one or more relatively global underlying variables that can account for the observed correlations among the analyzed items [10]. Thus, this analytic approach can clarify the extent to which one or more explanatory concepts or dimensions account for most of the shared variation among the variables. Composite scores combining such variables can then be used in further statistical modeling of an outcome of interest, reducing dimensionality of models and increasing estimate precision. Factor analysis was developed for intelligence testing [11], then expanded to other psychological variables, and now frequently used in validation of multiitem questionnaires in a variety of disciplines [13-16]. Factor analysis and related psychometric methods have been used to evaluate multiple clinical instruments used in arthritis, including the Arthritis Impact Measurement Scales Health Status Questionnaire (AIMS2) [17], Western Ontario and McMaster Universities Arthritis Index (WOMAC) [18], and Australian/Canadian Osteoarthritis Hand Index (AUSCAN) [19].

To our knowledge, these methods have only twice been applied to radiographic data, and then only for the hand $[20,21]$. However, the potential strength of factor analysis in understanding the whole body burden of radiographic $\mathrm{OA}(\mathrm{rOA})$ lies in its ability to account for presence and severity of rOA in multiple joint sites by including the full range of all of the individual radiographic scores. We were therefore interested in applying factor analytic methods to Kellgren-Lawrence global (KL, 0 to 4 ) and Burnett atlas joint features (0 to 3 ) radiographic grades $[22,23]$ across multiple joint sites as a way to formulate composite scores of multi-joint rOA, encompassing both presence and severity, using data from participants in the Johnston County Osteoarthritis Project (JoCo OA).

\section{Materials and methods}

The analysis used data from the $J o C o O A$, a populationbased prospective cohort study of non-institutionalized African American and white men and women, living in rural North Carolina, aged 45 years and older, both with and without OA, which has been described previously [24]. All participants signed informed consents, and completed two home interviews and one clinic visit with physical examination, including functional measures and radiographs, administered by trained study personnel. Multi-joint radiographs were added at the cohort enrichment (2003 to 2004) and second follow up (2006 to 2010), so data from these time points were used for the current analysis (total $n=2121$ ). Data from a given individual was included from only one time point.

Self-reported age, gender, and race were obtained from interviewer-administered questionnaires, while body mass index (BMI) was calculated in $\mathrm{kg} / \mathrm{m}^{2}$ from height $(\mathrm{cm})$ and weight $(\mathrm{kg})$ measured during clinic examination by trained study examiners. This cross-sectional analysis included demographic, clinical, and radiographic data collected at the same time for each participant (either during the 2003 to 2004 or 2006 to 2010 time period). The JoCo $O A$ has been continuously approved by the Institutional Review Boards of the University of North Carolina and of the Centers for Disease Control and Prevention in Atlanta, GA.

\section{Radiographs}

Posteroanterior radiographs of the bilateral hands were read for KL grade [22] at each of 30 joints (distal interphalangeal (DIP), proximal interphalangeal (PIP), metacarpophalangeal (MCP), CMC, thumb IP and MCP). Fixed flexion, weight-bearing posteroanterior views of the tibiofemoral joint (TFJ) using the Synaflexer ${ }^{\mathrm{TM}}$ device (CCBRSynarc, San Francisco, CA, USA) were read for KL grade. Sunrise views of the patellofemoral joints (PFJ) were read for osteophytes (OST) [25] using the Burnett atlas [23]. PFJ films were added later in the study and had not all been read at the time of this analysis (see also Figure 1). Anteroposterior supine pelvis films were used to assess KL grade at the hips; these films were not performed in women under age 50 years. Lateral lumbosacral spine (LS) films (taken with the participant lying on his/her left side) were read for OST and disc narrowing (DN) at five levels (L1/2 through L5/S1). Joints that had undergone replacement were not included, because no KL or OARSI score could be assigned. Individuals with radiographs suggestive of an underlying inflammatory condition were excluded. All films were read by a single experienced musculoskeletal radiologist (JBR) previously shown to have high intra- and inter-rater reliability ( $\kappa=0.89$ and 0.86 , respectively) [26].

Prior to factor analysis, a priori definitions for rOA were determined, such that 1 ) joints that were not included in any factor could still be included in a model to allow estimates to reflect the whole body burden of rOA and 2) sample characteristics for OA could be summarized. For the hand joints, TFJ, and hip, a KL grade of 2 or more was considered to be diagnostic of rOA in any given joint. For the PFJ, any OST of 2 or more was considered to indicate PFJ OA. LS OA was defined if both OST and DN graded 1 or more were present at a single level [9]. 


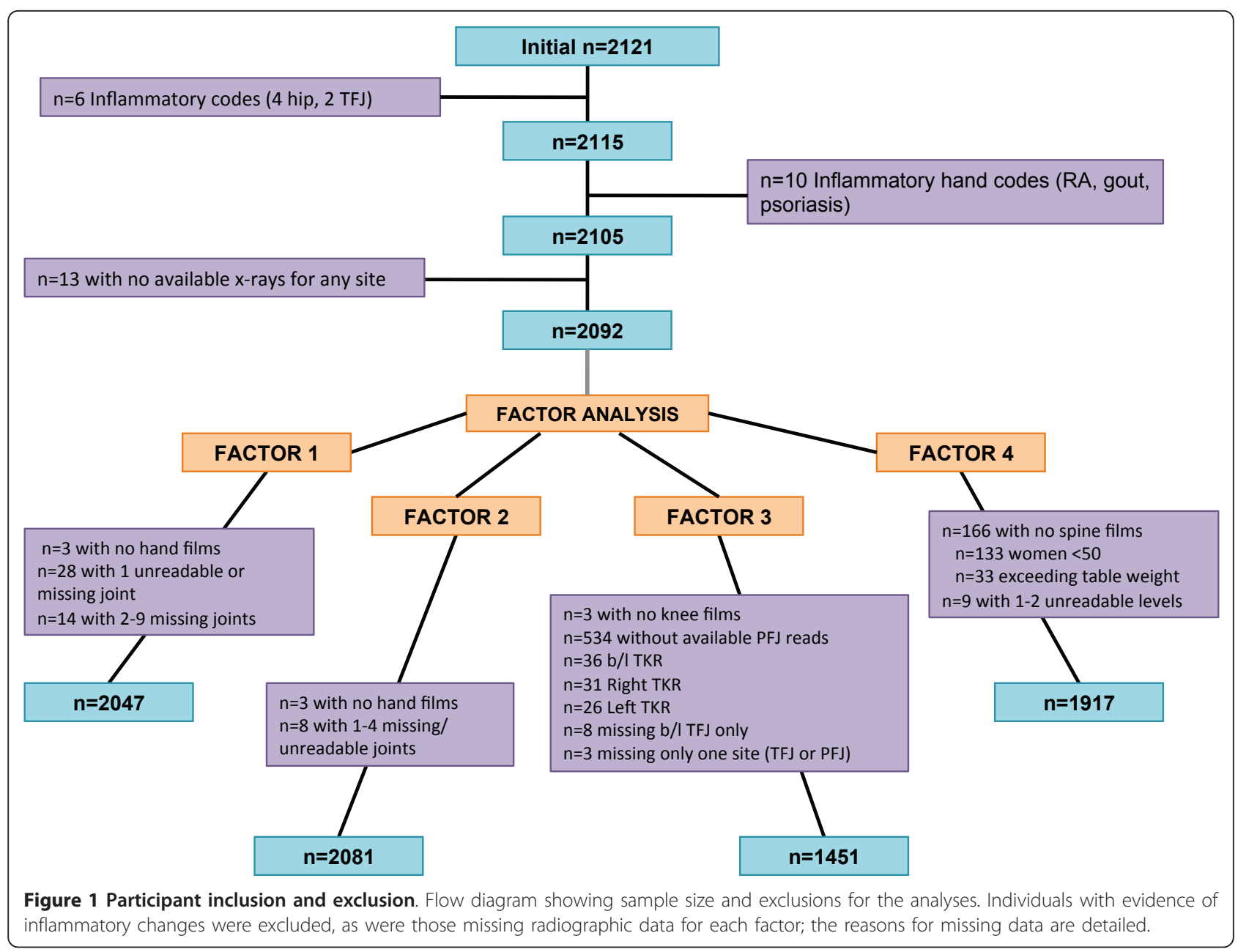

\section{Factor analysis}

In this paper, the term factor analysis refers to an exploratory common factor analysis, in which the factors represent hypothetical (latent) variables that are being estimated. Determination of the number of factors to retain can be performed utilizing eigenvalues, scree plots, factor interpretability, and/or parallel analysis, although there remains a level of subjectivity to this decision [10]. We used a scree plot, which allows visual comparison of relative eigenvalues [27]. Variables that did not load well $(\leq 0.4)$ or had cross-loadings, indicating weak relations to the latent variable, were dropped. An oblique rotation, which allows the factors to correlate with each other, was then applied. Higher order factor analysis was used to determine whether the identified factors represented a single latent variable (and could therefore be combined) or contained independent information that would be lost through combination. Cronbach's alpha statistic was calculated as a measure of internal consistency reliability for all factors. Separate factor analyses were performed for each gender (men and women), race (African American and white), age $(<65$ compared with $65+$ years) and cohort (cohort enrichment versus second follow-up cohorts) subgroup; qualitative comparisons of factor structure and Cronbach's alpha were performed. All analyses were performed in Stata 11.0 (StataCorp, College Station, TX, USA).

\section{Results}

\section{Sample characteristics}

The inclusion of subjects in the current analysis is presented, along with reasons for exclusion, in Figure 1. Sixteen individuals were excluded due to evidence of inflammatory disease on radiographs; the remainder of excluded individuals were missing radiographic data as shown. Detailed sample characteristics for the total sample $(n=2,092)$ and the subset with interpreted radiographs for all joint sites $(n=1,373)$ are shown in Table 1 . The subset with all radiographs was slightly older (67.3 versus 65.1 years), with a similar mean BMI and proportion of men and African Americans. About 45\% 


\begin{tabular}{|c|c|c|}
\hline & $\begin{array}{c}\text { Total sample }(n=2,092)^{*} \\
\text { Mean }(S D) \text { or } n(\%)\end{array}$ & $\begin{array}{l}\text { Subset with all radiographs }(n=1,373) \\
\text { Mean (SD) or } \%\end{array}$ \\
\hline Age (years) & $65.1(10.9)$ & $67.3(9.7)$ \\
\hline BMI $\left(\mathrm{kg} / \mathrm{m}^{2}\right)$ & $31.3(7.1)$ & $30.8(6.4)$ \\
\hline Male & $695(33.2)$ & $472(34.4)$ \\
\hline African American & 709 (33.9) & $438(31.9)$ \\
\hline $\mathrm{DIP} \mathrm{OA}^{\dagger}$ & $902(43.2)$ & $637(46.4)$ \\
\hline PIP OA & $595(28.5)$ & $419(30.5)$ \\
\hline MCP OA & $195(9.4)$ & $132(9.6)$ \\
\hline CMC1 OA & $577(27.7)$ & $416(30.3)$ \\
\hline TFJ OA & $822(39.8)$ & $554(40.4)$ \\
\hline PFJ Ost $>=2$ & $174(11.8)$ & $142(10.3)$ \\
\hline Hip OA & $643(33.8)$ & $475(34.9)^{\S}$ \\
\hline LS OA ${ }^{\ddagger}$ & $1,138(59.2)$ & $836(60.9)$ \\
\hline
\end{tabular}

*For total sample (at least one radiograph, see Figure), For LS OA $n=1,923 ; 2,068$ for TFJ OA; 1,901 for Hip OA; 1,481 for PFJ Ost; 2,088 for DIP and PIP OA; 2,086 for MCP and CMC OA

${ }^{+}$Where OA is defined as KL grade $>=2$ at any DIP, PIP, CMC, MCP, TFJ, or hip joint

${ }^{\ddagger}$ Defined as having at least one lumbar level (L1/2 to L5/S1) with both ost and DN OARSI grade $>=1$

${ }^{\S} \mathrm{Hip}$ OA $n=1,360$

BMI, body mass index; CMC, carpometacarpal joint; DIP, distal interphalangeal joint; LS, lumbosacral spine; MCP, metacarpophalangeal joint; OA, osteoarthritis; OST, osteophytes; PFJ, patellofemoral joint; PIP, proximal interphalangeal joint; SD, standard deviation; TFJ, tibiofemoral joint.

of the participants had OA of the DIP joints, 30\% had PIP OA, and $9 \%$ had MCP OA. Slightly under one third had CMC OA, while slightly over one third had hip OA. Forty percent had TFJ OA, about $10 \%$ had any PFJ OST grade 2 or more, and $60 \%$ had LS OA by our definition, with the subset overall similar to the total population (Table 1).

\section{Factor analysis}

All radiographic variables (KL or Burnett atlas joint features scores) were entered into a factor analysis simultaneously as continuous scores, such that each joint site had a score of 0 to 4 or 0 to 3 . We explored three-, four-, and five-factor solutions, as all of these were reasonable based on eigenvalues above 1 and scree plot findings (Figure 2). Balancing interpretability and simple structure, we selected a four-factor solution. Then, variables with weak or cross-loadings were dropped from the analysis. The hips had loadings of less than 0.2 in all solutions and were dropped. The first MCPs also had poor loadings $(<0.4)$, as well as cross-loadings, and were dropped. In a three-factor solution, the separate LS variables (first the DN grades, then the OST grades) had low loadings and so these were dropped, as were the CMC variables (loadings $<0.4$ ). However, when all LS variables were simultaneously included and a four-factor solution was used, these variables had acceptable loadings, as did the CMC joint, and all were retained in the present four-factor solution. In contrast, a five-factor solution caused the LS variables to cross-load onto factors 4 and 5 with lower loadings overall. An oblique rotation was then applied, as we deemed it unlikely that radiographic variables at different joint sites would be entirely independent. In this final solution, we identified four factors that can be thought of as latent variables underlying the individual radiographic variables contained in each (Table 2). The four factors were moderately correlated, with Pearson correlation coefficients ranging from 0.24 to 0.40 (Table 3).

The first can be defined as an IP/CMC Factor, and contains the thumb IP and CMC, DIPs 2 to 5 and PIPs

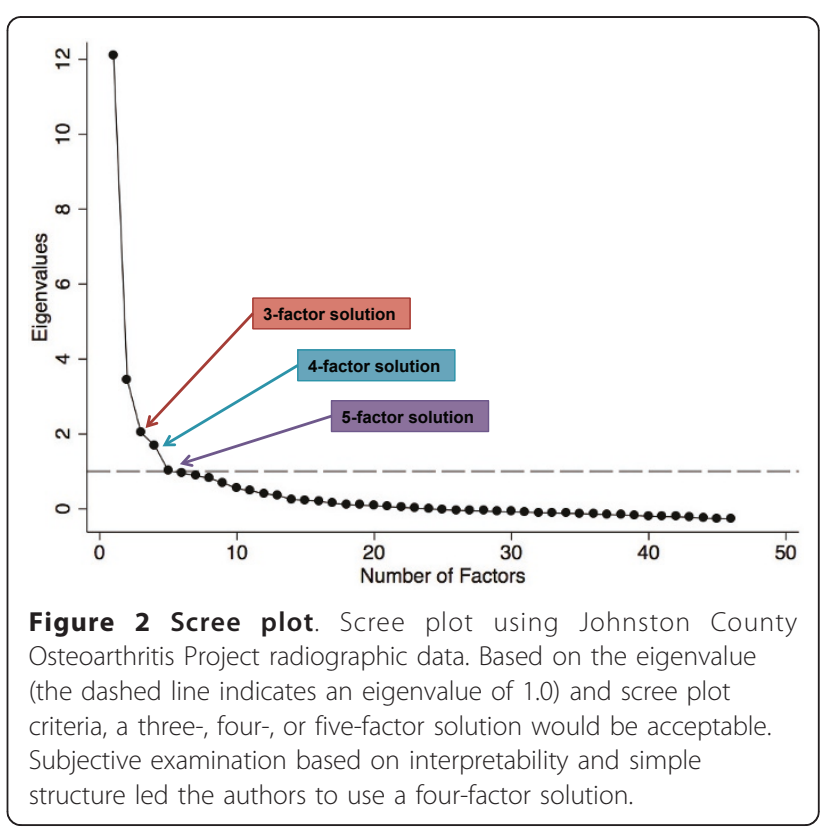


Table 2 Factor loadings* for each radiographic variable in the four-factor solution after oblique rotation

\begin{tabular}{|c|c|c|c|c|}
\hline \multirow[t]{2}{*}{ rOA Variable } & \multicolumn{4}{|c|}{ Factor } \\
\hline & IP/CMC & MCP & Knee & Spine \\
\hline$L 1^{\text {st }} I P$ & 0.512 & & & \\
\hline $\mathrm{R} 1^{\text {st }} \mathrm{IP}$ & 0.550 & & & \\
\hline L CMC 1 & 0.442 & & & \\
\hline R CMC 1 & 0.429 & & & \\
\hline $\mathrm{L} 2^{\text {nd }} \mathrm{DIP}$ & 0.833 & & & \\
\hline$L 3^{\text {rd }}$ DIP & 0.840 & & & \\
\hline$L 4^{\text {th }} \mathrm{DIP}$ & 0.814 & & & \\
\hline$L 5^{\text {th }} \mathrm{DIP}$ & 0.786 & & & \\
\hline $\mathrm{R} 2^{\text {nd }} \mathrm{DIP}$ & 0.796 & & & \\
\hline $\mathrm{R} 3^{\text {rd }} \mathrm{DIP}$ & 0.797 & & & \\
\hline $\mathrm{R} 4^{\text {th }} \mathrm{DIP}$ & 0.815 & & & \\
\hline $\mathrm{R} 5^{\text {th }} \mathrm{DIP}$ & 0.786 & & & \\
\hline $\mathrm{L} 2^{\text {nd }} \mathrm{PIP}$ & 0.682 & & & \\
\hline$L 3^{\text {rd }}$ PIP & 0.707 & & & \\
\hline$L 4^{\text {th }} P I P$ & 0.711 & & & \\
\hline$L 5^{\text {th }} \mathrm{PIP}$ & 0.669 & & & \\
\hline $\mathrm{R} 2^{\text {nd }} \mathrm{PIP}$ & 0.685 & & & \\
\hline $\mathrm{R} 3^{\text {rd }} \mathrm{PIP}$ & 0.694 & & & \\
\hline $\mathrm{R} 4^{\text {th }} \mathrm{PIP}$ & 0.749 & & & \\
\hline $\mathrm{R} 5^{\text {th }} \mathrm{PIP}$ & 0.636 & & & \\
\hline$L 2^{\text {nd }} M C P$ & & 0.595 & & \\
\hline $\mathrm{L} 3^{\text {rd }} \mathrm{MCP}$ & & 0.649 & & \\
\hline$L 4^{\text {th }} M C P$ & & 0.614 & & \\
\hline $\mathrm{L} 5^{\text {th }} \mathrm{MCP}$ & & 0.605 & & \\
\hline $\mathrm{R} 2^{\text {nd }} M C P$ & & 0.551 & & \\
\hline $\mathrm{R} 3^{\text {rd }} \mathrm{MCP}$ & & 0.589 & & \\
\hline$R 4^{\text {th }} M C P$ & & 0.671 & & \\
\hline$R 5^{\text {th }} M C P$ & & 0.602 & & \\
\hline Right TFJ & & & 0.699 & \\
\hline Left TFJ & & & 0.746 & \\
\hline Right PFJ avg ${ }^{\dagger}$ & & & 0.829 & \\
\hline Left PFJ $\mathrm{avg}^{\dagger}$ & & & 0.856 & \\
\hline L1/2 DN & & & & 0.555 \\
\hline L2/3 DN & & & & 0.697 \\
\hline L3/4 DN & & & & 0.622 \\
\hline L4/5 DN & & & & 0.474 \\
\hline L5/S1 DN & & & & 0.427 \\
\hline L1/2 OST & & & & 0.560 \\
\hline L2/3 OST & & & & 0.652 \\
\hline L3/4 OST & & & & 0.568 \\
\hline L4/5 OST & & & & 0.416 \\
\hline L5/S1 OST & & & & 0.384 \\
\hline
\end{tabular}

*Only loadings $>0.2$ are shown

${ }^{\dagger}$ PFJ presented for simplicity as average osteophytes across four surfaces (lateral femoral, lateral patellar, medial femoral, medial patellar), nearly identical loadings are obtained for individual surface scores.

CMC, carpometacarpal joint; DIP, distal interphalangeal joint; DN, disc narrowing; IP, interphalangeal joint; MCP, metacarpophalangeal joint; OST, osteophytes; PFJ, patellofemoral joint; PIP, proximal interphalangeal joint; rOA, radiographic osteoarthritis; TFJ, tibiofemoral joint.
Table 3 Pearson correlation coefficients between factors in the rotated four-factor solution

\begin{tabular}{lllll}
\hline & $\begin{array}{l}\text { IP/CMC } \\
\text { factor }\end{array}$ & $\begin{array}{l}\text { MCP } \\
\text { factor }\end{array}$ & $\begin{array}{l}\text { Knee } \\
\text { factor }\end{array}$ & $\begin{array}{l}\text { Spine } \\
\text { factor }\end{array}$ \\
\hline $\begin{array}{l}\text { IP/CMC } \\
\text { factor* }\end{array}$ & 1.0 & & & \\
MCP factor & 0.44 & 1.0 & & \\
Knee factor & 0.30 & 0.36 & 1.0 & \\
Spine factor & 0.24 & 0.30 & 0.40 & 1.0 \\
\hline
\end{tabular}

*IP/CMC factor: Thumb IP, DIP 2-5, PIP 2-5, CMC1; MCP factor: MCP 2-5, Knee factor: TFJ and PFJ; Spine factor: Disc space narrowing and osteophytes L1/2 to $L 5 / S 1$.

$\mathrm{IP}$, interphalangeal joint; MCP, metacarpophalangeal joint; PFJ, patellofemoral joint; PIP, proximal interphalangeal joint; TFJ, tibiofemoral joint.

2 to 5 of both hands (factor loadings 0.43 to 0.84 ). The lowest loadings on this factor were observed for the CMC (0.43 to 0.44), compared with 0.51 to 0.84 for the other included joints. The second factor is an MCP Factor, and includes the MCP joints of the second to fifth fingers of both hands (loadings 0.55 to 0.67 ). The third is the Knee factor, including the TFJ and PFJ of both knees (loadings 0.70 to 0.86 ). The fourth factor is the spine factor including DN and OST variables from the five LS levels L1/2 to L5/S1 (loadings 0.38 to 0.70 ). The lowest loadings were observed for DN and OST at the L4/5 and L5/S1 levels (0.38 to 0.47) compared with the other levels ( 0.55 to 0.70$)$, but for interpretability, all LS levels were retained. Cronbach's alpha statistic was calculated for each of the final factors to give a measure of reliability, and ranged from 0.80 for the spine factor to 0.95 for the IP/CMC factor (Table 4). The results were essentially unchanged when stratified by gender $(\alpha=$ 0.77 to 0.96$)$, race ( $\alpha=0.78$ to 0.96 ), age ( $\alpha=0.74$ to 0.95 ), or cohort ( $\alpha=0.77$ to 0.95 ) subgroups.

We were interested in the possibility of a single, higher order factor that could be defined as a "generalized rOA" score. However, in our analysis, higher order factor analysis of the four factors showed that they should not be combined into a single factor. For comparison, the individual factors had eigenvalues ranging from 11.7 (IP/CMC factor) to 1.7 (spine factor), compared with values not exceeding 1.1 for the higher order analysis. The loadings of the four factors on the higher order factor ranged from 0.47 to 0.56 . In addition, the reliability for this single higher order factor was lower than any of the individual factors at 0.65 .

\section{Discussion}

We have employed factor analysis as a way of understanding the latent factors underlying radiographic variables in OA. We report a four-factor solution as follows: 1) IP/CMC factor (20 joints), 2) MCP factor (eight joints), 3) knee factor (four joints), and 4) spine factor 


\begin{tabular}{|c|c|c|c|c|}
\hline Factor* & $\mathrm{n}$ (obs) ${ }^{\dagger}$ & $\mathrm{n}$ (variables) $^{\ddagger}$ & Cronbach's alpha & Average inter-variable correlation \\
\hline IP/CMC & 2047 & 20 & 0.95 & 0.51 \\
\hline MCP & 2081 & 8 & 0.81 & 0.35 \\
\hline Knee & 1451 & 4 & 0.85 & 0.59 \\
\hline Spine & 1917 & 10 & 0.80 & 0.29 \\
\hline
\end{tabular}

*IP/CMC factor: Thumb IP, DIP 2-5, PIP 2-5, CMC1; MCP factor: MCP 2-5, Knee factor: TFJ and PFJ; Spine factor: Disc space narrowing and osteophytes L1/2 to L5/ S1.

${ }^{\dagger}$ Number of observations with data for a factor

${ }^{\ddagger}$ Number of radiographic variables included in a factor

CMC, carpometacarpal joint; DIP, distal interphalangeal joint; IP, interphalangeal joint; MCP, metacarpophalangeal joint; PFJ, patellofemoral joint; PIP, proximal interphalangeal joint; TFJ, tibiofemoral joint.

including DN and OST (5 levels, 10 variables). Use of a composite (e.g., an average or a standardized score) for each of these four factors in a multiple regression model would result in representation of all $20+8+4+10=$ 42 underlying variables (or 37 distinct joint sites) through only four explanatory variables. Taking the MCP factor as an example, the individual scores from the eight MCP joints could be added and divided by eight, resulting in a single, average value for the MCP factor rather than eight individual scores. This allows consideration of the whole body burden of rOA in a parsimonious model, resulting in reduced dimensionality and increased precision of the resultant estimates. This is particularly important when considering a systemic outcome, such as a molecular or genetic biomarker, or a performance or disability score, which is likely influenced by the overall rOA burden and not only by the specific joint of interest in a study. The results were similar by age, between men and women, between African Americans and whites, and between members of the two cohorts.

Factor analysis involves some subjective decision-making, particularly when selecting the number of factors to retain and dropping variables that do not load well. The benefits of the four-factor solution are inclusion of the LS and CMC variables, which were not part of the three-factor solution. However, the spine factor has the lowest reliability and contains one variable (osteophytes at L5/S1) with loading less than 0.4 , and the reliability of the knee factor is slightly reduced in the four-factor $(\alpha=0.85)$ compared with the three-factor $(\alpha=0.87)$ solution. The elimination of the hip variables was robust and similar across all solutions, however, supporting the idea that the hip is not part of the generalized OA construct. Also dropping out in all solutions were the first MCP variables, for reasons that are not immediately obvious, as these joints were involved at a similar frequency to the other MCP joints.

Our results do not support a single underlying latent variable for all joint sites, and are therefore not consistent with the concept of "generalized OA." This is in agreement with a study by MacGregor, et al, who used structural equation modeling to assess relations between knee, hip, PIP, DIP, and CMC rOA (also using the KL grading system) in a population of female twins accounting for shared genetics [28]. The authors found that, while each individual joint site demonstrated genetic influence (heritability estimates 28 to $68 \%$ ), there was a moderate genetic correlation only between DIP and PIP joints, and little or no correlation between other joint sites [28]. MacGregor et al, conclude from their study that there was "little evidence of the phenotype "generalized OA," consistent with what we found using a different methodology in the present report.

The DIPs and PIPs have long been thought to group together, and bony enlargement of these sites is the basis for a clinical diagnosis of hand OA [29]. MCP involvement is generally thought to be less common than other hand joints and to represent a secondary OA process such as calcium pyrophosphate deposition disease (CPPD) or hemochromatosis. However, as shown by several studies reporting the patterns of hand OA, MCP involvement is not infrequent in radiographic or ultrasonographic OA $[6,30]$, with prevalence estimates ranging from $8 \%$ to $36 \%$ in Caucasian populations [9,31-33]. MCP rOA has been shown to be more common among African American compared with white women in one study [34]. Our preliminary work on the frequency of hand $\mathrm{rOA}$ in the JoCo $\mathrm{OA}$ showed that although African Americans were much less likely to have DIP or PIP rOA compared with whites, the frequency of MCP rOA was not different by race [35].

Principal components analysis (rather than exploratory factor analysis as described in the current paper) has been used in other studies of radiographic hand OA $[20,21]$. Marshall et al, reported on a principal components analysis of radiographic variables in the hand [20]. They identified a four-component model where the DIPs (second to fifth digits, right and left), PIPs (second to fifth digits, right and left), and MCP (only included the second and third bilaterally) joints each grouped onto one component and the thumb joints (IP, MCP, 
$\mathrm{CMC}$, and trapezioscaphoid) onto the fourth. In contrast to the current study, Marshall et al used binary variables in the factor analysis (rOA defined as $\mathrm{KL} \geq 2$ at each joint), which is not consistent with the assumptions of factor analysis and does not include information about KL severity. In addition, the authors of that study simplified their results to subgroup patients into finger only, thumb only, and thumb and finger together. Although such phenotyping is useful, it does not fully utilize the power of factor analysis to create meaningful composites. Hunter et al, using osteophyte and joint space narrowing scores in addition to KL scores in a principal components analysis of hand OA, chose a 10factor solution [21]. The DIP joints loaded on a single factor, as did the PIP joints, with other joints (CMC, individual MCPs, thumb IP) loading on separate factors, and these factors were then used in a genetic association study [21]. We found, in common with Marshall et al and Hunter et al, that the MCPs did not load onto the same factor as the IP joints. However, the DIP and PIP joints grouped together in our study along with the $\mathrm{CMC}$, and we did not identify a separate thumb factor, which may be due to our larger sample size or the above-noted differences in methodology.

Although we included data on the hips in our analysis, we found that the hip joints did not load onto any factor. There has long been controversy whether hip OA is part of the "generalized OA" construct, or a separate entity [36-41]. Our attempt to develop a composite measure of multi-joint OA has shown, in agreement with other researchers [6], that the hip is a separate entity, but it remains unclear whether this is a measurement issue or a true difference in the nature of $\mathrm{OA}$ at the hip compared with other sites. Arden, et al, in a study assessing different radiographic definitions of hip OA, found that composite measures such as the KL grade had superior construct and predictive validity compared with single radiographic features (such as osteophytes or joint space narrowing alone), and recommended such measures for defining incident hip rOA [42], supporting our use of this grading system. Hip OA is less influenced by obesity in comparison with knee OA [43-45], and may therefore have other unique risk factors that vary by gender and race. For example, among African Americans compared with Caucasians [46], we have reported a higher prevalence of specific radiographic features, such as superior joint space narrowing, previously found to be predictive of progression to hip replacement [47]. Other recently recognized aspects of hip anatomy, such as femoroacetabular impingement and hip shape as described through active shape modeling, may contribute to hip-specific OA risk [48-51] while not reflecting "generalized OA."

Limitations to the current study include the lack of PFJ joint space narrowing data (although PFJ osteophytes were included due to better reproducibility and associations with knee pain [25]), and of radiographs of other joint sites, such as the feet or cervical spine, although we did have radiographic data for many of the joint sites most commonly affected by rOA. Although we used primarily KL grades for the present analysis, use of individual radiographic features (osteophytes and joint space narrowing), could lead to different conclusions and will be the focus of future analyses. Differences in scaling can cause variables to group on a factor due to differences in scale alone, but while we had some radiographic grades that were based on a 0 to 3 scale while others were on a 0 to 4 scale, we did not observe groupings based solely on this difference in scaling. The factor structure presented here has not yet been replicated in an independent population, and should be considered specific to the $\mathrm{JOCO}_{\mathrm{O}}$ $O A$ study until replication has been confirmed. The factors we have identified should therefore not be used in other populations without confirmation of a similar structure. We have used only radiographic data in this analysis, although other projects are underway to consider symptoms and other variables of importance to an individual's experience of OA.

\section{Conclusions}

Combination of multiple radiographic variables using composite scores as described allows consideration of the whole body burden of rOA in parsimonious regression models, resulting in reduced dimensionality and increased estimate precision. This methodology provides a way to define more complete phenotypes in individuals with rOA in statistical models, thus improving study of systemic outcomes in this common and debilitating disease.

\section{Abbreviations}

BMI: body mass index; CMC: carpometacarpal joint; DIP: distal interphalangeal joint; DN: disc narrowing; IP: interphalangeal joint; KL: Kellgren-Lawrence; L1/2, etc: lumbosacral spine level; LS: lumbosacral spine; MCP: metacarpophalangeal joint; OA: osteoarthritis; OST: osteophytes; PFJ: patellofemoral joint; PIP: proximal interphalangeal joint; rOA: radiographic osteoarthritis; TFJ: tibiofemoral joint.

\section{Acknowledgements}

We would like to thank the staff and participants of the Johnston County Osteoarthritis Project without whom this work would not have been possible. Funding for this work was provided in part by: Nelson: American College of Rheumatology Clinical Investigator Fellowship Award 2009; NIH/ NIAMS Loan Repayment Award L30-AR056604

Jordan/Renner: CDC/Association of Schools of Public Health S043 and S3486 Jordan/Renner/Schwartz: NIAMS P60-AR30701

The funding sources were not involved in study design, data collection or interpretation, writing or approval of the manuscript for publication.

\section{Author details}

'Thurston Arthritis Research Center, University of North Carolina, 3300 Thurston Building CB 7280, Chapel Hill, NC, 27599, USA. ${ }^{2}$ Department of Health Behavior and Health Education, Gillings School of Global Public Health, University of North Carolina, 302 Rosenau Hall, Chapel Hill, NC, 
27599, USA. ${ }^{3}$ Department of Radiology, University of North Carolina, 101 Manning Drive, Chapel Hill, NC, 27514, USA. ${ }^{4}$ Department of Biostatistics, Gillings School of Global Public Health, University of North Carolina, $3106 \mathrm{E}$ McGavran-Greenberg Hall, Chapel Hill, NC, 27599, USA. ${ }^{5}$ Section of Musculoskeletal Disease, University of Leeds \& NIHR Leeds Musculoskeletal Biomedical Research Unit, Chapel Allerton Hospital, Chapeltown Road, Leeds, LS7 4SA, UK. ${ }^{6}$ Department of Medicine, Duke University Medical Center, 595 La Salle St, Durham, NC, 27710, USA.

\section{Authors' contributions}

AEN, RFDeV and JMJ were responsible for study conception and design, data acquisition, analysis and interpretation, drafting and critical revision for important content. PGC and VBK were responsible for study conception and design, drafting and critical revision for important content. JBR and TAS were responsible for data acquisition, analysis and interpretation, drafting and critical revision for important content. All authors have read and approved the final manuscript for publication.

\section{Competing interests}

The authors declare that they have no competing interests.

Received: 26 April 2011 Revised: 5 July 2011

Accepted: 25 October 2011 Published: 25 October 2011

\section{References}

1. Robert Adams: A treatise on rheumatic gout, or chronic rheumatic arthritis of all the joints. London: J John Churchill and Sons; 21873.

2. Kellgren JH, Moore R: Generalized osteoarthritis and Heberden's nodes. $\mathrm{Br}$ Med J 1952, 1:181-187.

3. Lawrence JS: Generalized osteoarthrosis in a population sample. Am J Epidemiol 1969, 90:381-389.

4. Felson DT, Couropmitree NN, Chaisson CE, Hannan MT, Zhang Y, McAlindon TE, LaValley M, Levy D, Myers RH: Evidence for a Mendelian gene in a segregation analysis of generalized radiographic osteoarthritis: the Framingham Study. Arthritis Rheum 1998, 41:1064-1071.

5. Meulenbelt I, Kloppenburg M, Kroon HM, Houwing-Duistermaat JJ, Garnero P, Hellio le Graverand MP, DeGroot J, Slagboom PE: Urinary CTX-II levels are associated with radiographic subtypes of osteoarthritis in hip, knee, hand, and facet joints in subject with familial osteoarthritis at multiple sites: the GARP study. Ann Rheum Dis 2006, 65:360-365.

6. Kraus VB, Kepler TB, Stabler T, Renner J, Jordan J: First qualification study of serum biomarkers as indicators of total body burden of osteoarthritis. PLoS One 2010, 5:e9739.

7. Hirsch R, Lethbridge-Cejku M, Scott WW, Reichle R, Plato CC, Tobin J, Hochberg MC: Association of hand and knee osteoarthritis: evidence for a polyarticular disease subset. Ann Rheum Dis 1996, 55:25-29.

8. Doherty M, Watt I, Dieppe P: Influence of primary generalised osteoarthritis on development of secondary osteoarthritis. Lancet 1983, 2:8-11.

9. Kraus VB, Jordan JM, Doherty M, Wilson AG, Moskowitz RW, Hochberg MC Loeser R, Hooper M, Renner JB, Crane MM, Hastie P, Sundseth S, Atif U: The Genetics of Generalized Osteoarthritis (GOGO) Study: Study Design and Evaluation of Osteoarthritis Phenotypes. Osteoarthritis \& Cartilage 2007, 15:120-127.

10. DeVellis RF: Factor Analysis. Scale Development: Theory and Applications. 2 edition. Thousand Oaks, CA Sage Publications, Inc; 2003, 102-137.

11. Thurstone LL: Multiple factor analysis. Psychol Rev 1931, 38:406-427.

12. Spearman C: Thurstone's work re-worked. Journal of Educational Psychology 1939, 30:1-16

13. Pickering PM, Osmotherly PG, Attia JR, McElduff P: An examination of outcome measures for pain and dysfunction in the cervical spine: a factor analysis. Spine (Phila Pa 1976) 2011, 36:581-588.

14. Lamers SM, Westerhof GJ, Bohlmeijer ET, Ten Klooster PM, Keyes CL: Evaluating the psychometric properties of the mental health Continuum-Short Form (MHC-SF). J Clin Psychol 2011, 67:99-110.

15. Fortier-Brochu E, Beaulieu-Bonneau S, Ivers H, Morin CM: Relations between sleep, fatigue, and health-related quality of life in individuals with insomnia. J Psychosom Res 2010, 69:475-483.

16. Kelton ML, LeardMann CA, Smith B, Boyko EJ, Hooper TI, Gackstetter GD Bliese PD, Hoge CW, Smith TC, Millennium Cohort Study Team: Exploratory factor analysis of self-reported symptoms in a large, population-based military cohort. BMC Med Res Methodol 2010, 10:94.

17. Meenan RF, Mason JH, Anderson JJ, Guccione AA, Kazis LE: The content and properties of a revised and expanded arthritis impact measurement scales health status questionnaire. Arthritis Rheum 1992, 35:1-10.

18. McConnell S, Kolopack P, Davis AM: The Western Ontario and McMaster Universities Osteoarthritis Index (WOMAC): a review of its utility and measurement properties. Arthritis Rheum 2001, 45:453-461.

19. Allen KD, DeVellis RF, Renner JB, Kraus VB, Jordan JM: Validity and factor structure of the AUSCAN Osteoarthritis Hand Index in a communitybased sample. Osteoarthritis \& Cartilage 2007, 15:830-836.

20. Marshall M, van der WD, Nicholls E, Myers H, Hay E, Dziedzic K. Radiographic hand osteoarthritis: patterns and associations with hand pain and function in a community-dwelling sample. Osteoarthritis Cartilage 2009, 17:1440-1447.

21. Hunter DJ, Demissie S, Cupples LA, Aliabadi P, Felson DT: A genome scan for joint-specific hand osteoarthritis susceptibility: The Framingham Study. Arthritis Rheum 2004, 50:2489-2496.

22. Kellgren JH, Lawrence JS: Radiological assessment of osteo-arthrosis. Ann Rheum Dis 1957, 16:494-502.

23. Burnett SJ, Hart DJ, Cooper C, Spector TD: A radiographic atlas of osteoarthritis London: Springer-Verlag; 1994.

24. Jordan JM, Helmick CG, Renner JB, Luta G, Dragomir AD, Woodard J, Fang F, Schwartz TA, Abbate LM, Callahan LF, Kalsbeek WD, Hochberg MC: Prevalence of knee symptoms and radiographic and symptomatic knee osteoarthritis in African Americans and Caucasians: The Johnston County Osteoarthritis Project. J Rheumatol 2007, 34:172-180.

25. Cicuttini FM, Baker JR, Hart DJ, Spector TD: Choosing the best method for radiological assessment of patellofemoral osteoarthritis. Ann Rheum Dis 1996, 55:134-136.

26. Jordan JM, Linder GF, Renner JB, Fryer JG: The impact of arthritis in rural populations. Arthritis Care Res 1995, 8:242-250.

27. Cattell RB: The scree test for the number of factors. Multivariate Behavioral Research 1966, 1:245-276.

28. MacGregor AJ, Li Q, Spector TD, Williams FM: The genetic influence on radiographic osteoarthritis is site specific at the hand, hip and knee. Rheumatology (Oxford) 2009, 48:277-280.

29. Altman R, Alarcon G, Appelrouth D, Bloch D, Borenstein D, Brandt K, Brown C, Cooke TD, Daniel W, Gray R: The American College of Rheumatology criteria for the classification and reporting of osteoarthritis of the hand. Arthritis Rheum 1990, 33:1601-1610.

30. Keen HI, Wakefield RJ, Grainger AJ, Hensor EM, Emery P, Conaghan PG: Can ultrasonography improve on radiographic assessment in osteoarthritis of the hands? A comparison between radiographic and ultrasonographic detected pathology. Ann Rheum Dis 2008, 67:1116-1120.

31. Kalichman L, Li L, Batsevich V, Malkin I, Kobyliansky E: Prevalence, pattern and determinants of radiographic hand osteoarthritis in five Russian community-based samples. Osteoarthritis Cartilage 2010, 18:803-809.

32. Zhang Y, Xu L, Nevitt MC, Niu J, Goggins JP, Aliabadi P, Yu W, Lui LY, Felson DT: Lower prevalence of hand osteoarthritis among Chinese subjects in Beijing compared with white subjects in the United States: the Beijing Osteoarthritis Study. Arthritis Rheum 2003, 48:1034-1040.

33. Dahaghin S, Bierma-Zeinstra SM, Ginai AZ, Pols HA, Hazes JM, Koes BW: Prevalence and pattern of radiographic hand osteoarthritis and association with pain and disability (the Rotterdam study). Ann Rheum Dis 2005, 64:682-687.

34. Sowers M, Lachance L, Hochberg M, Jamadar D: Radiographically defined osteoarthritis of the hand and knee in young and middle-aged African American and Caucasian women. Osteoarthritis Cartilage 2000, 8:69-77.

35. Nelson AE, Fang F, Renner JB, Woodard J, Hochberg MC, Helmick CG, Jordan JM: Racial differences in joint-specific radiographic hand osteoarthritis and self-reported hand pain: The Johnston County Osteoarthritis Project. Osteoarthritis \& Cartilage 2008, 15(supp C):C154-155.

36. Croft $P$, Cooper C, Wickham C, Coggon D: Is the hip involved in generalized osteoarthritis? Br J Rheumatol 1992, 31:325-328.

37. Jordan JM, Helmick CG, Renner JB, Luta G, Dragomir AD, Woodard J, Fang F, Schwartz TA, Nelson AE, Abbate LM, Callahan LF, Kalsbeek WD, Hochberg MC: Prevalence of hip symptoms and radiographic and symptomatic hip osteoarthritis in african americans and Caucasians: the johnston county osteoarthritis project. J Rheumatol 2009, 36:809-815. 
38. Villiaumey J: Is the hip involved in generalized osteoarthritis? $\mathrm{Br} J$ Rheumatol 1993, 32:85-86.

39. Ledingham J, Dawson S, Preston B, Milligan G, Doherty M: Radiographic patterns and associations of osteoarthritis of the hip. Ann Rheum Dis 1992, 51:1111-1116.

40. Kellgren JH, Moore R: Generalized osteoarthritis and Heberden's nodes. BMJ 1952, 1:181-187.

41. Dahaghin S, Bierma-Zeinstra SM, Reijman M, Pols HA, Hazes JM, Koes BW: Does hand osteoarthritis predict future hip or knee osteoarthritis? Arthritis Rheum 2005, 52:3520-3527.

42. Arden NK, Lane NE, Parimi N, Javaid KM, Lui LY, Hochberg MC, Nevitt M: Defining incident radiographic hip osteoarthritis for epidemiologic studies in women. Arthritis Rheum 2009, 60:1052-1059.

43. Cooper C, Inskip H, Croft P, Campbell L, Smith G, McLaren M, Coggon D: Individual risk factors for hip osteoarthritis: Obesity, hip injury and physical activity. Am J Epidemiol 1998, 147:516-522.

44. Sturmer T, Gunther KP, Brenner H: Obesity, overweight and patterns of osteoarthritis: the Ulm Osteoarthritis Study. J Clin Epidemiol 2000, 53:307-313.

45. Tepper S, Hochberg MC: Factors associated with hip osteoarthritis: data from the First National Health and Nutrition Examination Survey (NHANES-I). Am J Epidemiol 1993, 137:1081-1088.

46. Nelson AE, Braga L, Renner JB, Atashili J, Woodard J, Hochberg MC, Helmick CG, Jordan JM: Characterization of individual radiographic features of hip osteoarthritis in African American and White women and men: the Johnston County Osteoarthritis Project. Arthritis Care Res (Hoboken) 2010, 62:190-197.

47. Lane NE, Nevitt MC, Hochberg MC, Hung YY, Palermo L: Progression of radiographic hip osteoarthritis over eight years in a community sample of elderly white women. Arthritis Rheum 2004, 50:1477-1486.

48. Gosvig KK, Jacobsen S, Sonne-Holm S, Palm H, Troelsen A: Prevalence of malformations of the hip joint and their relationship to sex, groin pain and risk of osteoarthritis: a population-based survey. J Bone Joint Surg Am 2010, 92:1162-1169.

49. Gregory JS, Waarsing JH, Day J, Pols HA, Reijman M, Weinans H, Aspden RM: Early identification of radiographic osteoarthritis of the hip using an active shape model to quantify changes in bone morphometric features: can hip shape tell us anything about the progression of osteoarthritis? Arthritis Rheum 2007, 56:3634-3643.

50. Doherty M, Courtney P, Doherty S, Jenkins W, Maciewicz RA, Muir K, Zhang W: Nonspherical femoral head shape (pistol grip deformity), neck shaft angle, and risk of hip osteoarthritis: a case-control study. Arthritis Rheum 2008, 58:3172-3182.

51. Lynch JA, Parimi N, Chaganti RK, Nevitt MC, Lane NE, Study of Osteoporotic Fractures Research Group: The association of proximal femoral shape and incident radiographic hip OA in elderly women. Osteoarthritis Cartilage 2009, 17:1313-1318.

doi:10.1186/ar3501

Cite this article as: Nelson et al: Quantification of the whole-body burden of radiographic osteoarthritis using factor analysis. Arthritis Research \& Therapy 2011 13:R176.

\section{Submit your next manuscript to BioMed Central and take full advantage of:}

- Convenient online submission

- Thorough peer review

- No space constraints or color figure charges

- Immediate publication on acceptance

- Inclusion in PubMed, CAS, Scopus and Google Scholar

- Research which is freely available for redistribution

Submit your manuscript at www.biomedcentral.com/submit
Biomed Central 